\title{
A inserção da Mulher no Esporte e no automobilismo
}

\section{The insertion of women in sports and auto racing}

DOI: $10.46919 / \operatorname{archv3n1-001}$

Recebimento dos originais: 17/12/2021

Aceitação para publicação: 17/01/2022

\section{Eduardo Geller De Brida}

licenciatura em Educação Física pela Universidade FEEVALE e pós-graduação em Segurança Pública pela Faculdade FAVENI

SUSEPE - Superintendência dos Serviços Penitenciários

Rua Onze amigos, 934 - Bairro Vale Direito - Dois Irmãos/ RS

E-mail: eduardodebrida@gmail.com

\section{André Kristoschek Sperling}

bacharel em Ciências Jurídicas e Sociais pela Universidade do Alto Uruguai e das Missões - URI Santo Ângelo

SUSEPE - Superintendência dos Serviços Penitenciários

Rua Integração, 388 - Bairro Centro - Entre-Ijuís/ RS

E-mail: andrehksperling@ hotmail.com

\section{Juliano Alvarenga Duarte}

licenciatura em Educação Física

SUSEPE - Superintendência dos Serviços Penitenciários

Rua Santos Ferreira, 4100, bloco 6, apto 301- Bairro Estância Velha - Canoas/ RS

E-mail: julianoalvarengaduarte30@gmail.com

\section{Lenon Araujo Einhardt}

bacharel em Ciências Contábeis - Universidade do Alto Uruguai

SUSEPE - Superintendência dos Serviços Penitenciários

Rua Santos Ferreira, 4100, bloco 6, apto 301- Bairro Estância Velha - Canoas/ RS

E-mail: lenon-silveira@susepe.rs.gov.br

\section{Lucas Gracioli de Lima}

Formação acadêmica: Administração - UNISUL

SUSEPE - Superintendência dos Serviços Penitenciários

Rua Passo dos Weber, 950 - Santa Maria/ RS

E-mail: lucaslima77@hotmail.com

\section{Roger Cadena de Assunpção}

bacharel em Filosofia - PUCRS e bacharel em Ciências Jurídicas e Sociais - UFRGS

SUSEPE - Superintendência dos Serviços Penitenciários Rua Prof. Cristiano Fischer, 180 - Bairro Petrópolis - Porto Alegre/ RS

E-mail: roger.assunpcao@gmail.com

\section{Tiago Darold Cruz}

bacharel em Educação Física pela Faculdade Metodista de Santa Maria (FAMES)

SUSEPE - Superintendência dos Serviços Penitenciários 
Rua Pedro Santini, 3497, casa 78A - Bairro Cerrito - Santa Maria/ RS

E-mail: tiagoedfisica88@hotmail.com

Vinicius Santos dos Santos

bacharel em Educação Física - UFSM

SUSEPE - Superintendência dos Serviços Penitenciários

Rua Sete de Setembro, 140, apto 501 - Bairro Nossa Sra. das Graças

- Canoas/ RS

E-mail: santosdossantos@live.com

\title{
RESUMO
}

Considerando a relevância da participação do sexo feminino nas diversas áreas da sociedade contemporânea e, sobretudo, a crescente desmitificação conquistada nas mais variadas categorias esportivas ao longo do século XX, se alongando até a atualidade, o presente texto, pretende evidenciar, por meio de uma discussão bibliográfica, a realidade encontrada pelas mulheres inseridas nos segmentos esportivos e contextualizar a influência do esporte com as conquistas obtidas pela mulher ao longo do século. Ao caracterizar a mulher esportista na atualidade, são notórios, mesmo após todos os êxitos, direitos e conquistas de caráter social obtidos no século XX, que o sexo feminino ainda não obtém das mesmas "vantagens" e "facilidades" do sexo masculino, sendo necessário assim, um esforço grandioso destas para que possam acessar e permanecer nos desportos. Entretanto, no que se refere à influência do esporte perante uma sociedade igualitária, são evidentes os grandes feitos e valores que o esporte oportunizou e transpôs socialmente ao sexo feminino. Reiterando as históricas desvantagens sociais perante o homem na sociedade, podemos concluir que a mulher sempre buscou o seu espaço, seja por meio de lutas, movimentos ou protestos e, desta forma, o esporte emerge nos mesmos meandros. Nesse sentido, percebe-se na história grandes atletas que conseguiram direta ou indiretamente propiciar menores desigualdades e maiores oportunidades às mulheres de maneira geral, pois trouxeram representatividade e sensação de pertencimento a jovens e mulheres adulta, contribuindo, assim, para uma maior representação na sociedade e equidade com o sexo masculino.

Palavras-chave: Inserção, Sociedade, Mulher, Esporte, Automobilismo.

\begin{abstract}
Considering the relevance of the participation of female sex in various areas of contemporary society and, above all, the increasing demystification achieved in the most varied sports categories over the twentieth century, extending to the current status, or this text, seeks to demonstrate, through a bibliographic discussion, the reality found by the women inserted in our sports segments and contextualizing the influence of the sport with the achievements obtained by the woman or throughout the secular. To characterize a woman sportsman at the present time, notorious, same after all the successes, direct and achievements of social character obtained I do not know XX, that the feminine sex does not obtain the same "advantages" and "facilities" of the masculine sex, being necessary also, a great effort is being made so that you can access and stay with us. In the meantime, not that it refers to the influence of sports on an egalitarian society, it is evident that the great feits and values that are opportunely and socially transposed to the female sex. Reiterating the historical disadvantages sociais to man in society, we can conclude that women have always sought their space, whether through struggles, movements or protests and, in this way, or sport emerges in the same meanderings. In this sense, barnacle is a history of great athletes who will be able to directly or indirectly promote less inequalities and better opportunities for women in general, representing a group of representations and a feeling of belonging to young people and adult women, also contributing to a higher representation in society and equity as male sex.
\end{abstract}

Keywords: Insertion, Society, Woman, Sport, Motorsport. 


\section{INTRODUÇÃO}

Há tempos, é sabido que a mulher sempre teve suas ocupações designadas ao lar e aos serviços domésticos. Porém, com a evolução da sociedade foi possível se modificar isso através da evolução de seus direitos, conquistando igualdade e, neste sentido, se inserindo em atividades que predominantemente eram consideradas masculinas.

As modalidades esportivas, obviamente, não eram diferentes. Assim como todo o contexto social, se caracterizavam como práticas exclusivamente masculinas e, desta forma, não oportunizavam acessos às mulheres.

Goellner (2005) aponta que nem sempre foram - e algumas vezes ainda não é - iguais os direitos de acesso e participação de homens e mulheres no desporto, sejam nas competições profissionais, na educação física escolar, na divulgação oferecida pela mídia ou na própria premiação atribuída aos ganhadores e ganhadoras de eventos esportivas. Desta forma, o mesmo autor afirma que a estrutura conservadora da sociedade, não aceitava a participação das mulheres em alguns ambientes sociais, entre eles, os ambientes esportivos e, sobretudo, a ideia de sociedade nos meandros do século XX impunha que as únicas atribuições designadas às mulheres, eram as domésticas e maternas.

\section{DESENVOLVIMENTO}

A inserção da mulher brasileira no âmbito esportivo como um todo, data de meados século XIX, porém, é apenas no início do século XX que esta participação se amplia e, assim, ganha notoriedade. Com esta inclusão das mulheres no mundo de esportes de competição, onde nesta época elas são identificadas como seres de natureza frágil e de menor vivência no âmbito esportivo, elas passam a sofrer com alertas e discursos "machistas" que pregavam possíveis perigos que a prática competitiva poderia lhe causar, taxando-as com uma imagem masculinizada e virilizada.

Conforme Bitencourt, Granado e Carli (2018) a nadadora paulista Maria Lenck, então com 17 anos, veio a se firmar como a principal representação esportiva do sexo feminino no século XX, devido à mesma ter participado das Competições Olímpicas sediadas na cidade de Los Angeles, em 1932. Mesmo que inconscientemente, ela se incumbiu em atuar diretamente na divulgação da imagem da atleta feminina de competição, num tempo em que a mulher correspondia mais à assistência do que à prática das atividades esportivas em um grau competitivo.

Porém, mesmo com toda a divulgação e importância da participação de Maria Lenck no esporte, a imagem da mulher desportista desta época, como um todo, era impregnada por diversos dogmas, uma evidência disto, é o posicionamento oficial realizado pela Revista Brasileira de Educação Física, datada de 1941, onde a Revista orienta que todas mulheres devem evitar práticas violentas e de força, devido estas não serem práticas adaptáveis ao sexo feminino (GOELLNER, 2005). 
Com a modalidade esportiva automobilística, não foi diferente, de modo que quando o primeiro automóvel surgiu no Brasil e no Rio Grande do Sul no princípio do século XX, a mulher se caracterizava somente como passageira e espectadora.

Segundo Maduro, Mazo e Kilpp (2009) na segunda metade da década de 1920, o automobilismo de rua chegou a Porto Alegre, capital do Rio Grande do Sul e, após a década de 1930, a cidade transformouse em um polo do automobilismo nacional. Os autores ainda relatam que durante este período histórico do Brasil, “a prática esportiva se constituiu como um dos 'novos' costumes da modernidade. O esporte adquiriu as características de um fenômeno de massas no início do século XX, influenciando, de forma decisiva, a sociedade".

Complementando, Goellner (2005) afirma que nesses primeiros anos do século XX a popularização esportiva como um todo, passou a modificar as cidades brasileiras e impor uma transformação de suas realidades e, assim, fez com que os grandes centros e metrópoles do país ganhassem ares de modernidade e urbanização.

Retomando o enfoque ao cenário automobilístico, Maduro, Mazo e Kilpp (2009) afirmam que as mulheres somente alcançaram notoriedade no estado do Rio Grande do Sul, justamente a partir do ingresso como espectadoras de competições de rua protagonizadas pelos seus familiares, onde acompanhavam as corridas de seus pais, esposos ou irmãos. Desta forma, os autores destacam que a gaúcha Nilza Ruschel, natural de Venâncio Aires-RS, foi a primeira mulher piloto das corridas de rua porto-alegrenses a alcançar notoriedade, por volta do final da década de 1930, tendo boa presença nas competições automobilísticas até o ano de 1941.

A grande influenciadora de Nilza Ruchel no automobilismo foi a francesa Hellé Nice, piloto destacada mundialmente e apontada como a pioneira entre as mulheres no automobilismo mundial de elite, tendo disputado mais de 70 corridas. Hellé Nice chamava a atenção entre os pilotos brasileiros, com toda sua irreverência e extravagância, devido ela pilotar carros, fumar em público e usar unhas pintadas, realidade que não fazia parte do imaginário da sociedade brasileira da época. A piloto francesa esteve no Brasil em 1936 disputando duas provas de automobilismo, uma no Rio de Janeiro-RJ e outra em São PauloSP, ambas válidas pelo Grand Prix Mundial. Porém, mesmo durante este período de imersão da representação feminina na categoria automobilística em todo o Brasil, juntamente com o aparecimento de Hellé Nice e Nilza Ruschel, o automobilismo de rua porto-alegrense continuava a ser uma prática esportiva exclusiva de homens no fim da década de 1930:

O ato de dirigir um automóvel simbolizava uma idéia de apropriação, que refletia o modelo da sociedade, apenas mais um campo do protagonismo masculino, pois quem dirigia os automóveis eram os homens, as mulheres "iam à carona". As competições esportivas eram criadas por homens e disputadas por homens. Estes alegavam que as mulheres não tinham condições para concorrer, pois eram mais ‘fracas' e não existiam competições na categoria feminina. Então, elas ocupavam o 
espaço da "assistência" ou "apareciam" em lugares permitidos pela sociedade. No caso do automobilismo, as mulheres eram destacadas no grid (local de largada das provas), na entrega das premiações, como miss (madrinha) do evento, e nas gincanas. (MADURO, MAZO e KILPP, 2009, p. 3)

Com a entrada feminina neste cenário esportivo a partir dos anos 1930, a trajetória das mulheres no automobilismo de rua até meados dos anos 1970, excetuando-se em raríssimos casos isolados, não fugiam das representações anteriormente referenciadas, onde as mulheres restringiam-se apenas a participar da entrega das premiações aos vencedores, vestindo-se em traje de banho e com intenções puramente comerciais por parte dos organizadores das provas. Um exemplo disto é a competição das "Mil Milhas Brasileiras", cuja primeira prova foi realizada no ano de 1956 no autódromo de Interlagos em São Paulo, e até os dias de hoje, apresentam somente mulheres nas entregas das premiações. A diferença é que atualmente, não vemos mulheres apenas entregando troféus na prova, mas sim, competindo naturalmente entre os demais (MADURO, MAZO e KILPP, 2009).

Os mesmos autores ainda afirmam que as pilotos brasileiras ganharam destaque e se tornaram presenças constantes nas provas automobilísticas a partir do fim da década de 1970, ocupando espaços além dos tradicionalmente ocupados. Uma evidência disto é o que ocorreu no ano de 1979, em uma corrida de Rally na cidade de Canela - RS, onde seis duplas inteiramente femininas participaram da prova, número até então impensável em competições tradicionalmente masculinas.

Segundo Gollner (2005) na segunda metade do século XX, todo o crescimento geral do cenário esportivo feminino, veio a ocorrer especialmente por meio das conquistas da tenista brasileira Maria Esther Bueno, esta que conquistou o tricampeonato individual e o pentacampeonato de duplas nas quadras inglesas de Wimbledon durante os anos 1960. Outro fator apontado pelo autor foram as frequentes participações femininas nos jogos olímpicos que se deram a partir da década de 1980, evidenciado as potencialidades das mulheres em todos os esportes e, assim, incentivando novas adeptas a praticar as mais variadas categorias.

Atualmente, é possível destacar no automobilismo nacional, a piloto Maria Cristina Rosito, gaúcha que teve seu início no automóvel da mesma forma que várias outras pilotos, por meio de incentivo de seu pai o então piloto Raffaele Rosito e acompanhando as corridas dele nos anos 1980. Cristina Rosito, como é conhecida no meio, iniciou no automobilismo aos 11 anos de idade e já conta com mais de 20 anos de carreira e, atualmente, vem destacando-se como uma das principais pilotos do país (MADURO, MAZO e KILPP, 2009).

Em relação ao televisionamento e ao marketing diverso, Lara (2007) defende que nas representações da mídia automobilística, a mulher, assim como a visão da sociedade, foi evoluindo. Comerciais dos anos 1950 identificavam uma mulher prestativa e preocupada com o cumprimento das tarefas domésticas, assim trazendo bem estar a sua família, já nos anos 1960, a mulher se mostra incluída em serviços externos, se 
distanciando da identidade que teria somente dentro do lar, como, esposa e mãe, havendo então a evolução de identificação do sexo feminino. Em torno da década de 1980 os anúncios se aproximam aos da atualidade, onde a mulher é representada por uma figura de corpo fragmentado, concreto e praticamente sem voz, sendo valorizada puramente pela sua estética e aparência física.

A grande maioria dos anúncios televisivos procura traçar um perfil, que de certo modo, representa e identifica a imagem da mulher na sociedade brasileira, algumas características são, jovem, magra, branca, heterossexual, passiva, dependente, infantil, dócil, sensual, desejosa por seduzir, afetiva, maternal, cuidadosa, dona de casa, incompetente em outras funções, feliz e praticamente muda. Visando o olhar feminino nas montadoras automotivas, ao contrario do que se julgava anteriormente, a imagem de mulher sem iniciativa se contrasta com as pesquisas em concessionárias, onde mulheres estão optando por modelos de automóveis robustos e potentes, deixando de lado este paradigma de somente dirigir carros compactos e “fáceis de pilotar" (LARA, 2007).

Neste mesmo contexto, as montadoras de veículos trazem a visão da mulher colaboradora da empresa junto com grupos de mulheres formadores de opiniões, para assim, fidelizar um público feminino com a marca. Com isso, fica explícita a vontade de montadoras automotivas e agências de publicidade de reconhecer o público de mulheres que vem crescendo nesse segmento, tanto na área de colaboradoras da empresa, mas também, como fiéis clientes da marca (LARA, 2007).

\section{CONCLUSÃO}

Conforme visto anteriormente a mulher vem conquistando seu espaço no esporte e no automobilismo há muito tempo, vem sendo pioneira - entendimento corroborado na publicação do site Dicas AUTO/RE. Um dos fatos que mostram a mulher se inserindo neste mundo até então denominado masculino, foi uma invenção datada de 1903, feita pela norte-americana Mary Anderson. Mary em uma de suas viagens de bonde em Nova Iorque observou a dificuldade que motoristas tinham quando chovia, sendo preciso abrir as janelas para os condutores de bondes conseguissem enxergar, então, Mary inventou um braço oscilante com uma lâmina de borracha, para facilitar a condução dos veículos quando o tempo era chuvoso e, somente em 1916, o equipamento veio a se tornar padrão nos veículos americanos.

Segundo o texto de Rafaela Borges, postado no blog Mulher ao Volante, temos grandes nomes no cenário de automobilismo e motociclismo de competição brasileiro, tais como, além da já citada Maria Cristina Rosito, Beatriz Figueiredo, Débora Rodrigues, Helena Deyama e Sheren Bueno. Essas mulheres competem em modalidades diferentes, tendo sua singularidade em cada categoria, entre caminhões, carros, motos e em competições de Rally, elas demonstram técnica e ousadia. Mesmo estando inseridas no mundo automobilístico competitivo, e tendo a sua estabilidade na área, as mulheres não deixam de ter a sua vida como mães, estudantes e profissionais de outras áreas, devido a esta circunstância, elas relatam o quão mais 
fácil pode ser para o homem lidar somente com o automobilismo, pois sendo mulher as ocupações vão muito além das pistas.

Neste sentido, é possível se concluir ao término do presente estudo, que mesmo se encontrando historicamente em desvantagens sociais perante ao homem na sociedade, a mulher sempre buscou o seu espaço por meio de lutas, movimentos ou protestos. O feminismo se manteve incansável mesmo com os anos, sempre objetivado menor desigualdades e mais oportunidades, visando se igualar e aproximar-se ao que o homem representa em nossa sociedade. Mulheres esportistas mostraram que nem sempre o apoio vinha da família, tendo que conquistarem seus maiores feitos, conquistas, espaços e notoriedade, pelos seus próprios esforços na área em que competiam. Sabemos, também, que cada indivíduo é único e se difere dos demais, sendo que com as mulheres não poderia ser diferente e, desta forma, conforme a sociedade está e for evoluindo, haverá mais espaço para muitas mostrarem o seu talento e, provar, que há lugar para todos, não sendo necessário privilegiar ninguém. 


\section{REFERÊNCIAS}

BITENCOURT, Ana Paula; GRANADO, Amanda; CARLI, Carolina. Revista Maria Lenk: jogue e se informe como quiser. 2018. Disponível em: < https://www.monografias.ufop.br/handle/35400000/1777>. Acesso em: 10 nov. 2021.

GOELLNER, Silvana Vilodre. Mulher e esporte no Brasil: entre incentivos e interdições elas fazem histórias. Pensar a prática, Goiânia, v. 8, n. 1, p. 85-100, jan./jun. 2005. Disponível em: < http://www.revistas.ufg.br/index.php/fef/article/download/106/101>. Acesso em: 7 nov. 2020.

LARA, Andréa de Almeida. Representação de mulher nos comerciais de automóveis: garota é apenas equipamento opcional. 2007. 118f. Dissertação (Mestrado em Comunicação) - Curso de Pós-graduação em Comunicação, Faculdade de Comunicação, Universidade de Brasília, Brasília, 2007. Disponível em: <http://bdtd.bce.unb.br/tedesimplificado/tde_busca/arquivo.php?codArquivo=2697>. Acesso em: 14 nov. 2020.

MADURO, Paula A.; MAZO, Janice Z.; KILPP, Cecília E. A participação das mulheres no automobilismo de rua em Porto Alegre: de coadjuvantes a protagonistas. Revista brasileira de Ciência e Movimento, Brasília, v. 17, n. 3, p. 123-129, 2009. Disponível em: < http://portalrevistas.ucb.br/index.php/RBCM/article/viewFile/1005/1411>. Acesso em: 7 nov. 2020.

Sites

<http://www.dicasautore.com.br/publicador/CMS.do?idSecao=73E44E37-2979-9521-278889E554FEEB0B\&idMateria=C7464013-950A-4187-E682-9317578A61AF>. Acesso em: 15 nov. 2020. <http://carsale.uol.com.br/hotsite/mulher/mulher26.shtml> Acesso em: 15 nov. 2020. 